\title{
RESPIRATORY TOXICITY OF TIO, NANOPARTICLES AFTER INTRAVENOUS INSTILLATION: AN EXPERIMENTAL STUDY
}

\author{
Marta Hurbánková1, Katarína Volkovová2, Soňa Wimmerová1, Danica Henčekováa, Štefánia Moricová1 \\ ${ }^{1}$ Laboratory of Respiratory Toxicology, Faculty of Public Health, Slovak Medical University, Bratislava, Slovak Republic \\ ${ }^{2}$ Medical Faculty, Slovak Medical University, Bratislava, Slovak Republic
}

\section{SUMMARY}

Objective: Nanomaterials are materials consisting of particles having one or more dimensions smaller than $100 \mathrm{~nm}$. Nanoparticles (NP) have different properties and effects in comparison with the same particle materials of larger size. They can penetrate through various membranes and get from the bloodstream to other organs in the body. Therefore, in our experiment we have dealt with the impact of nanoparticles $\mathrm{TiO}_{2}$ instilled intravenously (i.v.) (to a tail vein of an animal) on the selected parameters of bronchoalveolar lavage (BAL). The aim of our study was to determine whether $\mathrm{TiO}_{2}$ nanoparticles do pass through the vascular system to the respiratory tract, and if so, how they affect the selected inflammatory and cytotoxic parameters of bronchoalveolar lavage.

Methods: Wistar rats were intravenously given a suspension of $\mathrm{TiO}_{2}$ nanoparticles in saline solution. This suspension contained $10 \%$ volume of rat serum in dose: $1.0 \%$ from LD50 $=0.592 \mathrm{mg} / \mathrm{kg}$ of animal body weight. After the time intervals $1,7,14$ and 28 days, the animals were sacrificed under anaesthesia; bronchoalveolar lavage was performed and the BAL cells were isolated. We have examined these markers: differential count of BAL cells - alveolar macrophages (AM), polymorphonuclear leukocytes (PMNL), lymphocytes (Ly); viability and phagocytic activity of AM; proportion of immature cells and cathepsin $D$ enzyme levels.

Results: Regarding the respiratory toxicity of $\mathrm{TiO}_{2}$ nanoparticles we have found that $\mathrm{TiO}_{2}$ nanoparticles are relatively inert. BAL examined parameters (except the immature form of AM) were not significantly changed after 28 days of instillation compared to the control group. We found that the $\mathrm{TiO}_{2}$ nanoparticles used in our study were transferred from the bloodstream to the respiratory tract, but in a 28-day phase after i.v. instillation have been largely eliminated by the defence mechanism from the respiratory tract.

Conclusions: We suggest low biopersistence and relatively rapid elimination of $\mathrm{TiO}_{2}$ nanoparticles from the lung under used experimental conditions.

Key words: $\mathrm{TiO}_{2}$ nanoparticles, intravenous instillation, bronchoalveolar lavage, inflammatory and cytotoxic parameters

Address for correspondence: M. Hurbánková, Laboratory of Respiratory Toxicology, Faculty of Public Health, Slovak Medical University, Limbová 12, 83301 Bratislava, Slovak Republic. E-mail: marta.hurbankova@szu.sk

https://doi.org/10.21101/cejph.a5222

\section{INTRODUCTION}

Nanoparticles (NPs) are substances (particles) that are less than $100 \mathrm{~nm}$ in size in more than one dimension. The European Commission defines nanomaterial as a natural, incidental or manufactured material containing particles, in an unbound state or as an aggregate or agglomerate and where, generally for $50 \%$ or more of the particles in the number size distribution, one or more external dimensions is in the size ranging from 1-100 $\mathrm{nm}$ (1).

They can be spherical, tubular, or irregularly shaped and can exist in fused, aggregated or agglomerated forms. Entrance roads of nanoparticles into the organism are through the skin, lungs and by engulfment. The parameters of NPs that are relevant to health effects are nanoparticle size, chemical composition, surface characteristics, and shape.

Substances consisting of NP have different properties than the same substances composed of larger particles, e.g. microparticles of micrometre size. Particles and NP of the same substance can have completely different characteristics and effects on the organism (2-4).

They may present new health risks for humans and other animal species or plants. As a matter of fact, it may happen that the normal human immune mechanisms will not be able to adequately respond to the newly created particles. Moreover, NPs can be released into the environment $(2,4-6)$.

In addition, NPs are used in cosmetics and sunscreens, textiles, coatings, some food and energy technologies, as well as in some medical products (probes, display techniques etc.) and medicines (therapy and diagnosis).

Nanoparticles can have comparable dimensions as some biological molecules and can interact with them. In humans and in other living organisms they may move inside the body, reach blood and organs such as liver or heart, and may also penetrate through cell membranes. Insoluble nanoparticles may have a greater impact on health because they can persist in the body for long periods of time $(2,5,7,8)$. 
Non-soluble NPs may remain in lungs, gastrointestinal tract or brain for a long time; they are phagocytosed by professional macrophages of the immune system but interact with cells of the epithelium, the interstitial tissue and vascular cells allowing pro-inflammatory reactions of these cells. In addition, NPs can bind to proteins or translocate them into the circulation and reach secondary target organs like liver, spleen, kidneys, heart, and brain. In some cases (environmental or occupational exposure), they might represent a potential health hazard by inhalation $(9,10)$.

Inflammation due to the oxidative stress caused by nanoparticles from the occupational and environmental pollution consequently leads to a number of different diseases, including cardiovascular disease, asthma, cancer and chronic obstructive pulmonary disease. Pollution of nanoparticles could cause cardiovascular disease either through lung inflammation or through the direct effect of bloodborne particles, leading to the deterioration of coronary artery disease or increased blood clotting $(7,11)$.

Occupations such as workers in construction work, decorators and painters, welders, workers in nanotechnology, professional drivers (exposed to exhaust gas in maintenance and repair of cars), workers exposed to raw NPs and waste in working process, hairdressers, researchers, healthcare personnel in therapy and diagnostics etc. are also exposed to nanoparticles (12).

Titanium dioxide dust, when inhaled, has been recently classified by the International Agency for Research on Cancer (IARC) as an IARC Group 2B carcinogen possibly carcinogenic to humans. The findings of the IARC are based on the discovery that high concentrations of powdered and ultrafine titanium dioxide dust caused respiratory tract cancer in rats exposed by inhalation and intratracheal instillation (13).

The series of biological events or steps that produce the rat lung cancers (e.g. particle deposition, impaired lung clearance, cell injury, fibrosis, mutations, and ultimately cancer) have also been observed in people working in dusty environments. Therefore, the observations of cancer in animals were considered by IARC as relevant to people occupationally exposed to titanium dioxide dust. For example, titanium dioxide production workers may be exposed to high dust concentrations during packing, milling, site cleaning and maintenance, if there are insufficient dust control measures in place. However, it should be noted that the human studies conducted so far do not suggest any association between occupational exposure to titanium dioxide and an increased risk for cancer. The safe use of nanoparticle sized titanium dioxide, which can penetrate the body and reach internal organs, has been clarified. It has also been reported that titanium dioxide nanoparticles cause genetic damage in mice, suggesting that humans may be at risk of cancer or genetic disorders resulting from the exposure $(5,8,11,13,14)$.

In the medical field $\mathrm{NPs} \mathrm{TiO}_{2}$ are currently considered a relatively inert carrier for therapeutic and diagnostic pharmaceuticals, and they are also presumed for intravenous (i.v.) administration. Because they have nano dimensions, they probably can penetrate through various membranes and pass from the bloodstream to other organs in the body (15). Therefore, in our experiment we have dealt with the impact of $\mathrm{NP} \mathrm{TiO}_{2}$ instilled i.v. (to a tail vein of an animal) on the selected parameters of bronchoalveolar lavage (BAL) (16). The aim of the study was to determine whether the nanoparticles $\mathrm{TiO}_{2}$ investigated by us, do pass through the vascular system to the respiratory tract, and if so, how they affect the selected inflammatory and cytotoxic parameters of bronchoalveolar lavage; to compare the results of examined BAL parameters influenced by $\mathrm{TiO}_{2}$ with a control group; to find out changes in inflammatory and cytotoxic BAL parameters after exposure to $\mathrm{TiO}_{2}$ nanopartices in the acute phase (one day) and subacute phases ( 7 , 14 and 28 days after i.v. administration) - time dependence; and to find out which BAL parameters play a major role in the defence mechanisms following the exposure to nanoparticles. The present study is not concerned with the kinetics of $\mathrm{TiO}_{2}$ in the body nor with the determination of the presence of $\mathrm{TiO}_{2}$ nanoparticles in the pulmonary tissue of experimental animals.

\section{MATERIALS AND METHODS}

In our study nanoparticles of $\mathrm{TiO}_{2}$ have a particle size in the range of $15-60 \mathrm{~nm}$ and their surface is $1 \mathrm{~g}$ nanoparticles $=61$ $\mathrm{m}^{2}$. Wistar rats were intravenously given a suspension of $\mathrm{TiO}_{2}$ $(1.0 \%$ of LD $50=0.592 \mathrm{mg} / \mathrm{kg}$ of animal body weight $)$ and after the time intervals of $1,7,14$ and 28 days, the animals were (eight animals per each group) sacrificed under intraperitoneal anaesthesia (10\% solution of Ketamine - Narkamonand, 2\% solution Xylazine - Rometar administered according to animal weight), BAL was performed and the cells were isolated. Wistar rats of the control group of animals were intravenously given the same volume of saline solution containing $10 \%$ rat serum $(1,800 \mu \mathrm{l}$ of saline solution $+200 \mu \mathrm{l}$ of rat serum $)$ as groups with a suspension of $\mathrm{TiO}_{2}$.

We examined a differential count of BAL cells - alveolar macrophages (AM), polymorphonuclear leukocytes (PMNL), lymphocytes (Ly); viability and phagocytic activity of AM; proportion of immature cells and cathepsin D (Cat D) enzyme levels. The BAL fluid cells were determined in Bürker's chamber and differential counting of macrophages, PMNL, Ly and immature cells in the BAL fluid was performed on May-Grünwald GiemsaRomanowski stained preparations, counting 200 cells. Prior to that, the cells were cytocentrifuged on one slide by a Cytospin (Shandon) centrifuge.

The phagocytic activity of AM was investigated via modified method by Fornůsek et al. using 2-hydroxyethyl methacrylate particles from fyNeosys Prague. Fifty millilitres of particles in phosphate-buffered saline (PBS) were added to $100 \mathrm{ml}$ of BAL fluid and incubated for $60 \mathrm{~min}$ at $37^{\circ} \mathrm{C}$, and shook at short intervals. Staining was performed by the May-Grünwald GiemsaRomanowski method. Cells were considered positive when they phagocytized three or more particles (17).

To determine the viability of AM, $200 \mu$ of $0.25 \%$ erythrosine solution was added to $200 \mu \mathrm{l}$ aliquots of the cell suspension. The number of viable and non-viable cells was counted using Bürker's chamber. To investigate Cat D activity a BAL cell suspension was prepared, measured in Triton X-100 extracts, and stored at $-75^{\circ} \mathrm{C}$. A detailed description of the mentioned methodology can be found in papers by Hurbánková et al. (18, 19) and Dziedzic et al. (20).

For statistical analysis (Mann-Whitney test) the SPSS software - version 19 was used. All tests were done at a significance level $\alpha=0.05$ (if the calculated $p$ value was less than $\alpha$, the result was considered statistically significant). 


\section{RESULTS}

The differential cell count of bronchoalveolar lavage (BAL) AM, PMNL and Ly is an important indicator of cellular analysis of BAL. Exposure to harmful substances can cause change in the differential number of BAL cells $(16,20)$. In our case, in the group influenced by the $\mathrm{TiO}_{2}$ suspension, AM statistically significantly decreased after 24 hours, 7 and 14 days and Ly statistically significantly increased in the same time period. PMNL were not significantly affected (Table 1).

Increased number of immature forms of AM are found in need of intense inflammatory response (20). Regarding the immature forms of $\mathrm{AM}$ in our experiment influenced with $\mathrm{TiO}_{2}$ suspen- sion, these BAL parameters were significantly affected only in 28-day time interval after i.v. instillation. Probably in this time period (the situation after the initial inflammatory response), AM increase was required.

Reducing the viability and phagocytic activity of AM may result in attenuated clearance of inhaled materials, which may lead to an increase of effective dose of nanoparticles. The viability of AM in our case showed a significant reduction after 1, 7 and 14 days of i.v. instillation $\mathrm{TiO}_{2}$ suspension. After 28 days of $\mathrm{TiO}_{2}$ instillation, results were not significantly changed (Table 2).

The phagocytic activity of AM was significantly suppressed 7 days after dosing of $\mathrm{TiO}_{2}$ (this condition may result in lower

Table 1. BAL parameters (alveolar macrophages, polymorphonuclear leukocytes and lymphocytes) 1, 7, 14 and 28 days after i.v. $\mathrm{TiO}_{2}$ NP instillation compared to the control

\begin{tabular}{|c|c|c|c|c|c|c|c|c|c|c|}
\hline \multirow{2}{*}{$\begin{array}{l}\text { Time } \\
\text { of exposure }\end{array}$} & & \multicolumn{2}{|c|}{ AM percentage } & \multirow{2}{*}{ Sig } & \multicolumn{2}{|c|}{ PMNL percentage } & \multirow{2}{*}{ Sig } & \multicolumn{2}{|c|}{ Ly percentage } & \multirow{2}{*}{ Sig } \\
\hline & & Control & $\mathrm{TiO}_{2}$ & & Control & $\mathrm{TiO}_{2}$ & & Control & $\mathrm{TiO}_{2}$ & \\
\hline \multirow{3}{*}{1 day } & $1^{\text {st }} Q$ & 98.00 & 92.00 & \multirow{3}{*}{$\downarrow S$} & 0.00 & 2.00 & \multirow{3}{*}{$\uparrow N S$} & 0.25 & 2.00 & \multirow{3}{*}{$\uparrow S$} \\
\hline & Med & 98.00 & 94.00 & & 0.00 & 0.25 & & 1.00 & 3.50 & \\
\hline & $3^{\text {rd }} Q$ & 99.75 & 97.25 & & 1.00 & 3.50 & & 2.00 & 4.00 & \\
\hline \multirow{3}{*}{7 days } & $1^{\text {st }} Q$ & 98.00 & 93.00 & \multirow{3}{*}{$\downarrow S$} & 1.00 & 1.00 & \multirow{3}{*}{$\uparrow N S$} & 1.00 & 2.00 & \multirow{3}{*}{$\uparrow S$} \\
\hline & Med & 98.00 & 96.00 & & 1.00 & 1.00 & & 1.00 & 2.00 & \\
\hline & $3^{\text {rd }} Q$ & 98.00 & 97.00 & & 1.00 & 2.00 & & 1.00 & 6.50 & \\
\hline \multirow{3}{*}{14 days } & $1^{\text {st }} Q$ & 99.00 & 96.00 & \multirow{3}{*}{$\downarrow S$} & 0.00 & 0.00 & \multirow{3}{*}{$\uparrow N S$} & 0.00 & 0.25 & \multirow{3}{*}{$\uparrow S$} \\
\hline & Med & 99.50 & 97.50 & & 0.00 & 0.50 & & 0.00 & 1.50 & \\
\hline & $3^{\text {rd }} Q$ & 100.00 & 99.00 & & 0.75 & 1.00 & & 1.00 & 3.50 & \\
\hline \multirow{3}{*}{28 days } & $1^{\text {st }} Q$ & 98.00 & 94.00 & \multirow{3}{*}{$\downarrow N S$} & 0.00 & 0.00 & \multirow{3}{*}{$\uparrow N S$} & 0.00 & 1.00 & \multirow{3}{*}{$\uparrow N S$} \\
\hline & Med & 99.00 & 96.00 & & 0.00 & 1.00 & & 1.00 & 3.00 & \\
\hline & $3^{\text {rd }} Q$ & 100.00 & 99.00 & & 0.00 & 1.00 & & 2.00 & 5.00 & \\
\hline
\end{tabular}

S - statistically significant; NS - non-significant; $\downarrow$ - decrease of values; $\uparrow$ - increase of values; numerical data represent the median, 1st and 3rd quartile; AM - alveolar macrophages; PMNL - polymorphonuclear leukocytes; Ly - lymphocytes.

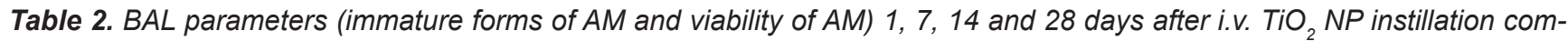
pared to the control

\begin{tabular}{|c|c|c|c|c|c|c|c|}
\hline \multirow{2}{*}{$\begin{array}{l}\text { Time } \\
\text { of exposure }\end{array}$} & & \multicolumn{2}{|c|}{ Immature forms of AM percentage } & \multirow{2}{*}{ Sig } & \multicolumn{2}{|c|}{ Viability of AM percentage } & \multirow{2}{*}{ Sig } \\
\hline & & Control & $\mathrm{TiO}_{2}$ & & Control & $\mathrm{TiO}_{2}$ & \\
\hline \multirow{3}{*}{1 day } & $1^{\text {st }} Q$ & 10.00 & 9.75 & \multirow{3}{*}{$\uparrow N S$} & 76.25 & 56.75 & \multirow{3}{*}{$\downarrow S$} \\
\hline & Med & 13.50 & 16.50 & & 80.50 & 64.00 & \\
\hline & $3^{\text {rd }} Q$ & 16.50 & 23.75 & & 84.00 & 69.25 & \\
\hline \multirow{3}{*}{7 days } & $1^{\text {st }} Q$ & 10.25 & 11.25 & \multirow{3}{*}{$\uparrow N S$} & 78.00 & 64.00 & \multirow{3}{*}{$\downarrow S$} \\
\hline & Med & 11.50 & 12.00 & & 79.00 & 65.00 & \\
\hline & $3^{\text {rd }} Q$ & 12.75 & 15.00 & & 80.75 & 77.00 & \\
\hline \multirow{3}{*}{14 days } & $1^{\text {st }} Q$ & 10.75 & 13.00 & \multirow{3}{*}{$\downarrow N S$} & 78.00 & 62.00 & \multirow{3}{*}{$\downarrow S$} \\
\hline & Med & 16.00 & 15.00 & & 80.00 & 69.00 & \\
\hline & $3^{\text {rd }} Q$ & 19.75 & 17.00 & & 85.75 & 77.25 & \\
\hline \multirow{3}{*}{28 days } & $1^{\text {st }} Q$ & 9.00 & 14.00 & \multirow{3}{*}{$\uparrow S$} & 62.00 & 66.00 & \multirow{3}{*}{ NS } \\
\hline & Med & 12.00 & 18.00 & & 72.00 & 68.00 & \\
\hline & $3^{\text {rd }} Q$ & 17.00 & 24.00 & & 78.00 & 75.00 & \\
\hline
\end{tabular}

S - statistically significant; NS - non-significant; $\downarrow$ - decrease of values; $\uparrow$ - increase of values; numerical data represent the median, 1 st and 3rd quartile; AM - alveolar macrophages. 
Table 3. BAL parameters (phagocytic activity of $A M$ and Cathepsin D activity) 1, 7, 14 and 28 days after i.v. TiO ${ }_{2} N P$ instillation compared to the control group

\begin{tabular}{|c|c|c|c|c|c|c|c|}
\hline \multirow{2}{*}{ Time of exposure } & & \multicolumn{2}{|c|}{ Phagocytic activity of AM percentage } & \multirow{2}{*}{ Sig } & \multicolumn{2}{|c|}{$\begin{array}{l}\text { Cathepsin D activity } \\
\text { (Utyr.mg proteins }{ }^{-1} \text { ) }\end{array}$} & \multirow{2}{*}{ Sig } \\
\hline & & Control & $\mathrm{TiO}_{2}$ & & Control & $\mathrm{TiO}_{2}$ & \\
\hline \multirow{3}{*}{1 day } & $1^{\text {st }} Q$ & 48.50 & 45.25 & \multirow{3}{*}{$\downarrow N S$} & 17.93 & 50.40 & \multirow{3}{*}{$\uparrow S$} \\
\hline & Med & 50.00 & 48.00 & & 36.66 & 76.45 & \\
\hline & $3^{\text {rd }} Q$ & 51.50 & 49.75 & & 42.21 & 90.89 & \\
\hline \multirow{3}{*}{7 days } & $1^{\text {st }} Q$ & 44.00 & 18.25 & \multirow{3}{*}{$\downarrow S$} & 30.86 & 76.66 & \multirow{3}{*}{$\uparrow S$} \\
\hline & Med & 47.50 & 31.00 & & 40.42 & 82.53 & \\
\hline & $3^{\text {rd }} Q$ & 48.00 & 37.25 & & 70.80 & 109.16 & \\
\hline \multirow{3}{*}{14 days } & $1^{\text {st }} Q$ & 25.00 & 30.00 & \multirow{3}{*}{$\uparrow N S$} & 42.10 & 75.25 & \multirow{3}{*}{$\uparrow S$} \\
\hline & Med & 29.50 & 31.50 & & 53.15 & 79.53 & \\
\hline & $3^{\text {rd }} Q$ & 34.50 & 39.50 & & 68.04 & 102.13 & \\
\hline \multirow{3}{*}{28 days } & $1^{\text {st }} Q$ & 15.00 & 18.00 & \multirow{3}{*}{$\uparrow N S$} & 55.22 & 49.91 & \multirow{3}{*}{$\uparrow N S$} \\
\hline & Med & 18.00 & 20.00 & & 70.27 & 93.18 & \\
\hline & $3^{\text {rd }} Q$ & 24.00 & 22.00 & & 77.73 & 126.90 & \\
\hline
\end{tabular}

S - statistically significant; NS - non-significant; $\downarrow$ - decrease of values; $\uparrow$ - increase of values; numerical data represent the median, 1 st and 3 rd quartile; AM - alveolar macrophages.

clearance of inhaled materials), but after 14 and 28 days the ability of phagocytosis was the same as in the control group.

Cathepsin D is a lysosomal enzyme that is released into BAL in case of damage of lung tissue. BAL cells influenced by some pollutants significantly contribute to the increased activity of lysosomal enzymes in BAL - especially macrophages. The increase of activity of lysosome enzymes is a good indicator of cell activation (especially AM), and reflects the degree of defence lung capability. Cat D is a major enzyme involved in the degradation of proteins in lysosomes. It is essential for proteolysis of proteins which regulates cell growth and tissue homeostasis $(18,21)$. In our case the level of Cat D enzyme was significantly increased only one day after 1,7 , and 14 days of i.v. instillation.

BAL examined parameters (except the immature form of AM) were not significantly changed after 28 days of instillation compared to the control group (Table 1, 2, 3).

\section{DISCUSSION}

Some materials can become toxic if they are inhaled in the form of nanoparticles. Currently, inhalation is the main route of human exposure to nanoparticles. Inhaled NP may cause lung inflammation and other lung diseases. They probably can accumulate in the lungs and then potentially move to other organs such as brain, blood system, heart, liver, spleen, and possibly to foetus in pregnant women. Information on behaviour of nanoparticles in the body is still scarce and therefore the assessment of the health implications of nanoparticles is very important (2).

For these reasons we wanted to investigate whether nanoparticles $\mathrm{TiO}_{2}$ examined in our study can pass through the vascular system to the respiratory tract - for example when applied in form of injectable nanomedicaments.

Trouiller et al. also found higher concentrations of markers of inflammation and oxidative stress in the mice that had been exposed to titanium dioxide nanoparticles. This has led the re- searchers to a suggestion that the toxicity of the particles could be caused by their ability to elicit an inflammatory response (22).

In our previous study, examined BAL parameters after intratracheal instillation of $\mathrm{TiO}_{2}$ in acute and subacute phases showed statistically significant changes, suggesting ongoing inflammatory, cytotoxic processes and oxidative "burning" in lung tissue (18).

Oxidant stress placed on lung tissue after exposure to nanoparticles yields superoxide anion, which can be subsequently converted to hydrogen peroxide. In the presence of iron, a constituent of tobacco smoke, the Haber-Weiss reaction may then result in formation of hydroxyl radicals that can cause DNA strand breaks. Hydrogen peroxide released by activated macrophages and lipid peroxidation through reactive aldehydes may place additional oxidant stress in the lungs and thus eventually results in malignant transformation of the epithelia lining in the airways. "The novel principle is that titanium by itself is chemically inert. However, when the particles become progressively smaller, their surface, in turn, becomes progressively bigger and in the interaction of this surface with the environment, oxidative stress is induced." $(23,24)$.

The lungs are often a major target organ for the toxic effects of many atmospheric pollutants, both gaseous and particulate in nature. The lungs respond continually to chemical and physical stimuli. Not all the responses evoked by substances are injurious. Many responses and changes in the lungs are not clearly definable as lung disease or damage but can be discerned by bronchoalveolar lavage (BAL). In many cases, the cellular constituents obtained in the lavage provide a good indication of lung injury. Examination of the amount and the type of cells obtained via BAL, as well as their viability and activity, helps to understand the extent of the harmful effects in lungs caused by inhaled noxious substances $(20,24,25)$. According to Dziedzic et al. long-term recruitment of PMNL might be an important factor in prediction of lung metaplastic processes (20).

AM play a significant role in the mechanism which regulates the response to noxious substance exposure. Besides their phago- 
cytic nature, AM are also important immuno-regulatory cells involved in the defence mechanisms, as well as in the pathogenesis of numerous lung diseases. Activated AM release various cytokines, reactive oxygen intermediates and other mediators of the inflammatory reaction $(20,26,27)$.

AM constitute an important and frequently utilized tool for examination of cytotoxicity. AM are the predominant cells present in BAL and changes in their number or function are factors determining lung injury and characterizing the pathogenesis of such a response. During the migration of monocytes into tissues, come to a further differentiation until they become multifunctional tissue macrophages. They may at this stage be regarded as "immature macrophages". During the immune process, the number of "immature macrophages" significantly increases. Reduction in macrophage amount, the viability or the phagocytic capacity may result in an impaired clearance and in the accumulation of inhaled materials $(20,27-29)$.

Further human studies are needed in order to truly understand the health effects of titanium dioxide nanoparticles. "It could be that a certain portion of spontaneous cancers are due to this exposure. Some people could be more sensitive to nanoparticles exposure than the others" (30). Recently, new toxicity data on the adverse pulmonary effects of exposure to $\mathrm{TiO}_{2}$ have indicated the need for revised risk management standards including recommended exposure limits (RELs) for fine (defined as primary particle diameters $>100 \mathrm{~nm}$ ) and ultrafine or nanoscale (defined as primary particle diameters $<100 \mathrm{~nm}$ ) $\mathrm{TiO}_{2}$. Results from experimental animal studies show presence of persistent pulmonary inflammation and lung tumors for both fine and ultrafine $\mathrm{TiO}_{2}$ in which the dose-response best correlated with particle surface area $(22,31)$.

Nanoparticles may represent new potential health risks. In fact, it may happen that the normal human defence mechanisms are unable to adequately respond to these newly created particles that may have unique features, which the human organism has not met.

The European Commission has expressed caution about "sufficiency" of legislation regarding the effects of nanoparticles and protection from risks of nanotechnology upcoming products.

Therefore, the impact of nanoparticles on health becomes a public health issue, resulting in an important requirement for research. It should be particularly targeted at monitoring of the effects of new developed nanoparticles and at experimental studies in vitro, in vivo, and clinical epidemiological studies.

\section{CONCLUSION}

We found that $\mathrm{TiO}_{2}$ nanoparticles used in our study were transferred from the bloodstream to the respiratory tract, but in a 28-day phase after i.v. instillation have been largely eliminated from the respiratory tract by the defence mechanism. BAL examined parameters (except the immature form of AM) were not significantly changed after 28 days of instillation compared to the control group.

\section{Acknowledgement}

„This article was created as a part of the project "Centre of Excellence of Environmental Health", ITMS No. 26240120033, based on the support of operational research and development programme financed by the European Regional Development Fund and was also supported by NanoTest EU Project (7FP), No.19-40-10)".

\section{Conflict of Interests}

None declared

\section{REFERENCES}

1. Commission Recommendation of 18 October 2011 on the definition of nanomaterial. Off J Eur Union. 2011 Oct 20;54(L 275):38-40.

2. Allhoff F, Lin P, Moore D. What is nanotechnology and why does it matter? From science to ethics. Chichester: Wiley-Blackwell; 2010.

3. Donaldson K, Stone V, Tran CL, Kreyling W, Borm PJ. Nanotoxicology. Occup Environ Med. 2004 Sep;61(9):727-8.

4. Jain KK. Nanotechnologies. In: Jain KK. The handbook of nanomedicine. Totowa: Humana Press; 2008. p. 7-61.

5. Borm PJA, Muller-Schulte D. Nanoparticles in medicine. In: Donaldson K, Borm P, editors. Particle toxicology. Boca Raton: CRC Press Taylor \& Francis Group; 2007. p. 387-411.

6. Kuka S, Hurbánková M, Drličková M, Baška T, Hudečková H, Tatarková Z. Nanomaterials - a new and former public health issue. The case of Slovakia. Cent Eur J Public Health. 2016 Dec;24(4):308-13.

7. Yu MH. Environmental toxicology: biological and health effects of pollutants. 2nd ed. Boca Raton: CRC Press; 2005.

8. Nel A, Xia T, Mädler L, Li N. Toxic potential of materials at the nanolevel. Science. 2006 Feb;311(5761):622-7.

9. Warheit DB, Brock WJ, Lee KP, Webb TR, Reed KL. Comparative pulmonary toxicity inhalation and instillation studies with different $\mathrm{TiO} 2$ particle formulations: impact of surface treatments on particle toxicity. Toxicol Sci. 2005;88(2):514-24.

10. Warheit DB, Webb TR, Reed KL, Frerichs S, Sayes CM. Pulmonary toxicity study in rats with three forms of ultrafine-TiO2 particles: differential responses related to surface properties. Toxicology. 2007;230(1):90-104.

11. Oberdörster G, Maynard A, Donaldson K, Castranova V, Fitzpatrick J, Ausman K, et al.; ILSI Research Foundation/Risk Science Institute Nanomaterial Toxicity Screening Working Group. Principles for characterizing the potential human health effects from exposure to nanomaterials: elements of a screening strategy. Part Fibre Toxicol. 2005 Oct 6;2:8. doi:10.1186/1743-8977-2-8.

12. Hurbánková M, Hrašková $D$, Moricová Š. Occupational exposure to nanoparticles. Prac Lek. 2014;66(2-3):78-84. (In Slovak.)

13. IARC Working Group on the Evaluation of Carcinogenic Risks to Humans. Carbon black, titanium dioxide, and talc. IARC Monogr Eval Carcinog Risks Hum. 2010;93:1-413.

14. Baan R, Straif K, Grosse Y, Secretan B, El Ghissassi F, Cogliano V, et al. Carcinogenicity of carbon black, titanium dioxide, and talc. Lancet Oncol. 2006;7(4):295-6.

15. Borm PJA, Robbins D, Haubold S, Kuhlbusch T, Fissan H, Donaldson $\mathrm{K}$, et al. The potential risk of nanomaterials: a review carried out for ECETOC. Part Fibre Toxicol. 2006 Aug 14;3:11. doi:10.1186/1743-89773-11.

16. Neeraj V, editor. Pulmonary nanomedicine: diagnostics, imaging, and therapeutics. Boca Raton: Pan Stanford Publishing; 2012.

17. Fornůsek L, Větvička V, Kopeček J. Phagocytosis of the peritoneal leukocytes - a new single method. Imunol Zprav. 1982;13(3-4):67- 8. (In Czech.)

18. Hurbánková M, Černá S, Kováčiková Z, Wimmerová S, Hrašková, D, Marcišiaková J, et al. Effect of TiO2 nanofibres on selected bronchoalveolar parameters in acute and subacute phase - experimental study. Cent Eur J Public Health. 2013;21(3):165-70.

19. Hurbánková M, Kaiglová A. Compared effects of asbestos and wollastonite fibrous dusts on various biological parameters measured in bronchoalveolar lavage fluid. J Trace Microprobe Tech. 1999;17(2):233-43.

20. Dziedzic D, Wheeler CS, Gross KB. Bronchoalveolar lavage: detecting markers of lung injury. In: Corn M, editor. Handbook of hazardous materials. San Diego: Academic Press; 1993. p. 99-111.

21. Černá S, Hurbánková M, Kováčiková Z, Beňo M, Wimmerová S, Kiss T, et al. Changes in the cytotoxic parameters of bronchoalveolar lavage of rats after 6 month exposure to refractory ceramic fibres, amosite asbestos and cigarette smoke. Chem Listy. 2007;101 Suppl:172-3. 
22. Trouiller B, Reliene R, Westbrook A, Solaimani P, Schiestl R H. Titanium dioxide nanoparticles induce DNA damage and genetic instability in vivo in mice. Cancer Res. 2009; 69(22):8784-9.

23. Kelly FJ, Mudway IS. Particle-mediated extracellular oxidative stress in the lung. In: Donaldson K, Borm P, editors. Particle toxicology. Boca Raton: CRC Press/Taylor \& Francis Group; 2007. p. 89-117.

24. Witschi H. Tobacco smoking, In: Gardner DE, editor. Toxicology of the lung. Boca Raton: CRC/Taylor \& Francis Group; 2006. p. 623-47.

25. Hurbankova M, Volkovova K, Hraskova D, Wimmerova S, Moricova S. Respiratory toxicity of Fe3O4 nanoparticles: experimental study. Rev Environ Health. 2017;32(1-2):207-10.

26. Hurbánková M, Kaiglová A, Buchancová J. Cytokines - the important biomarkers of lung injury after exposure to industrial fibrous dusts. Acta Med Martin. 2001;1(1):19-24.

27. Tarkowski M, Gorski P. Macrophage activity in asbestos related diseases. Pol J Occup Med Environ Health. 1991;4(2):115-25.
28. Cohen MD. Pulmonary immunotoxicology. In: Gardner DE, editor. Toxicology of the lung. Boca Raton: CRC/Taylor \& Francis Group; 2006. p. 351-417.

29. Hurbánková M, Tátrai E, Černá S, Six E, Kováčiková Z, Kyrtopoulos S. Inflammatory and cytotoxic effects as well as histological findings of selected industrial fibrous dusts in fischer rats after intratracheal instillation. Biologia. 2004; 59(6):769-78.

30. Murashov V, Howard J. Essential features of proactive risk management. Natur Nanotechnol. 2009;4(8):467-70.

31. Occupational exposure to titanium dioxide. Current Intelligence Bulletin 63. Cincinnati: NIOSH; 2011. 